\title{
Language Evolution in Biolinguistics from a Multi-Factor Perspective
}

\author{
Zhenyi Shao \\ College of Humanities, Tiangong University, Tianjin, China \\ Email: zhenyishao2019@163.com
}

How to cite this paper: Shao, Z.Y. (2019) Language Evolution in Biolinguistics from a Multi-Factor Perspective. Open Access Library Journal, 6: e5867.

https://doi.org/10.4236/oalib.1105867

Received: October 17, 2019

Accepted: November 4, 2019

Published: November 7, 2019

Copyright $\odot 2019$ by author(s) and Open Access Library Inc.

This work is licensed under the Creative Commons Attribution International License (CC BY 4.0).

http://creativecommons.org/licenses/by/4.0/

(c) () Open Access

\begin{abstract}
Biolinguistics is an interdisciplinary subject derived from the interaction of biology and linguistics. In 1967, after the publication of Biological Foundations of Language by Lenneberg E.H., the vision of Language study has been introduced into the field of biology. Later, Chomsky proposed the term of language faculty and regarded language as "an organ of the body". Different from traditional linguists' description of the rules of language externalization, Chomsky focuses on the biological mechanism of internalized language. The challenge of theory of evolution in biology has also enriched the study of the origin and evolution of language. This thesis will begin with the mythological origin and philosophical foundation of language, chase the challenge of evolutionary theory, and discuss two groups of basic properties of language, which is unity and diversity, recursiveness and thinking, so as to further study the relation between language and its biological basis, that is, from language and speech organ, language and thought to language and gene, to analyze the uniqueness of human language competence.
\end{abstract}

\section{Subject Areas}

Linguistics

\section{Keywords}

Language Evolution, Language Properties, Language Faculty, Biolinguistics, Uniqueness

\section{Introduction}

Before we talk about the biolinguistics, we need to figure out what is language in biology or to say biological language. Different with communicative language, language in biology is an internalized biological mechanism stored in the human 
brain. Language includes internalized language, i.e. internal biological language mechanism, and externalized language, which is used to refer to any symbolic system, or any form of communication or expression. Both of them constitute human language. To sum up, language is a specific object in the biological field. This linguistic study perspective is called "biolinguistics".

Among puzzles of language, there are three fundamental questions to answer: 1) How does language generate and evolution; 2) Why are there so many forms of language; 3) Is Language Unique to human. These questions will be discussed below.

\section{The Origin of Language-From Myth, Philosophy and Biological Attribute}

In the Old Testament, language is recorded as a gift to Adam, and for a long time it is a mono-language commonly shared by people. When human built the Tower of Babel so that they might reach closer to heaven, lord believes them disrespectful and dispersed them, and confounded their languages so they could no longer communicate. Connected with the god and myth, the topic of origin of language turns to be more mysterious and forbidden, so that two well-known edicts were published-Société de Linguistique de Paris in 1866 and the Philological Society of London in 1872-that forbade all members from presenting speeches on the topic [1]. Therefore, arguments of origin and development of language play an important role in moral philosophy at 18 th century.

Actually, the study of origin and development can be traced back on a long history. It has experienced a repulsive time for self-respecting linguists' studies but then it became fashion again. In 18th century, "philosophy" can fall into two parts, the study of natural phenomena i.e. "natural philosophy", and the study of man i.e. "moral philosophy" - which is the science connecting the principles of nature [2]. At that time, everything done relies on speculation mainly from the field of philosophy rather than science. The Enlightenment prevailed and promoted rationalism and advocated language as one of the most significant achievement of man. In moral philosophy, analysis of origin of language corresponds to the search for the basic principle of human nature. Adam Smith says: "philosophy is the science connecting the principles of nature". Although, there exist two different aspects of philosophy to study origin of language, fundamentally, it can believe that science set up as a new branch compared with philosophy, but the scientific approach is still applied, which the experimental method used in moral philosophy presupposes a fundamental similarity in the subject matter of moral and natural philosophy. So, given that no matter how we investigate and study the origin and development of language, we all will be starting with the nature of language then collecting data and analyzing them in a scientific way.

Since ancient Greece, philosophy prevails, and philosophers all apply to answer three fundamental questions: 1) who I am? (problem of ontology); 2) Why 
am I Here? (problem of epistemology); 3) Where am I going? (problem of ethics). Philosophy guides the development of human world view, cover with widely scope of varies subjects, neither of each field can avoid to answer these questions. Natural science is to explore this earth from a very objective perspective to give an explicit result, but it still bears the task to reveal the basic and intrinsic appearance of objects in the world to answer the first question. Linguistics is deeply impacted by philosophy, logistics and semiology respectively. From ancient times, religion and philosophy have regarded language as a faculty bestowed uniquely and suddenly on our own species, primarily as a mode of thought with communication as a byproduct [3]. This view deeply persists among some scientists and linguists and is counter to the theory of evolution, but it has been argued by Chomsky, he starts from language itself as a unique mental process and with intrinsic biological properties. Language derives in brain with evolutionary trajectories, including the generative capacities to travel mentally in time and space and into the minds of others.

Chomsky has proposed three problem of biolinguistics thinking deeply for the nature of language, which he called as 1) Humboldt's problem-what constitutes language; 2) Plato's problem-how language is learned and to what extent experience has to do with that knowledge; 3) Cartesian problem-how is language used. After that Chomsky extend the three questions into five in minimalist. However, in essence, the three-core question of biolinguistics has close connection with philosophy. Chomsky put three fundamental philosophy questions into language, he uses the concept of knowledge of language to relate language, human and world together, so that answer the following questions of "what is language"; "how language is acquired" and "how language is used". The first question aims to ask the nature of world and human language; the second question is designed to chasing the defining feature of human being and moreover to ask the characteristic of human being existing in the world; the last question is for the purpose of asking human's role of subjective initiative in the practice of the world, and to answer the reason of social characteristics of language users.

Chomsky states that Bloomfield treats language as the sum of all utterance occurred in speech community, and grammar is the sequence of meaningful form, which is analyzing language from a static view. On the contrary, Chomsky divides language into externalized language and internalized language, on account of that he takes the dynamic property and static property of language into consideration, and notices the organic nature of language, its process and realization. He advocates that the study of language essence is inseparable from the dynamic disclosure of language's intrinsic nature, language occurrence and language use.

Chomsky has often characterized language as "an organ of the body" and on a par with the digestive and immune systems [4]. He tries to account for the ability that children have to use language. By the age of four, most children have the ability to construct complex sentences. This ability usually precedes literacy, 
mathematical skills, and even some motor skills. Later on, he turns his eyes on the biological evolution of language; children are genetically born with language ability, maybe it can explain why human being is so different and superior than animals, but when is it occurred, how does it evolved since ancient time that our ancestor depart from Africa, and what it is in brain, these are unknown. If we want to talk about the origin and the development of language, we should trace back on the evolutionary history and find more evidences of homo sapiens and other relative species.

\section{Challenge to Theory of Evolution}

Language research has long been inextricably linked with biology. Darwin proposed that the evolution of language is a gradual process of natural selection; Bickerton believed that human language is the product of the evolution of primitive mother tongue; Liberman proposed that the unique mechanism of human vocal cords in the process of vocal cord evolution are of great value to the study of the origin of language; Pinker believed that human language ability is both the product of instinct and the result of evolution. Chomsky believes that the evolution process of language is a discontinuous, slight mutation, and human beings are born with a language faculty. He attributes the origin of language to the basic properties of human language.

Evolutionary theory, however, has itself undergone changes. Darwin himself once wrote "If it could be demonstrated that any complex organ existed... my theory would absolutely break down. But I can find no such case" [5]. Nevertheless, the emergence of a new organ in one single step is much more complex than we think so as language. Language is also undeniable complex, given that its rules of operation are still not well understood after some 60 years of Chomskian linguistics [3].

Within the 60 years, scientists constantly find many new evidences, some hypotheses have been overturned, and other new hypothesis has raised. Challenges of theory of evolutionary have experienced with Modern Synthesis and the later extended Evolutionary Synthesis incorporating ideas from genetics, embryology, and population thinking, raising the possibility of more rapid change than that implied by the selection of random mutations [6]. But it still neither can fully explain how language appeared among in such a mutational way nor to explain why the time is in so short an evolutionary period. Pinker and Bloom [7] discuss an amount of neo-Darwinian possibilities including the view that language is a "spandrel"-a byproduct of the brain's evolved capacity for computation [8], which spandrel originally is an architectural term, but borrowed in biology to refer to a byproduct of a feature that evolved for different reasons, such as use of the nose to hold glasses. However, they come to a conclusion that "there is every reason to believe that language has been shaped by natural selection as it is understood within the orthodox "synthetic" or "neo-Darwinian" theory of evolution". Gould and Eldredge [9] further proposed "punctuated evolution"- suggested 
that evolution can proceed in spurts, most species will exhibit little net evolutionary change for most of their geological history and new species evolve relatively rapidly followed by a period of stasis with little genetic change. But they clearly stated that this kind of evolutionary is nothing with ecological catastrophe or sudden genetic change. Chomsky's theory absorbs Evo-devo, that is, complex changes can "complex changes can occur through mutations in regulatory genes that orchestrate the timing of development rather than through the emergence of new genes" [3]. Nevertheless, actual evolutionary is that such mutations, neither apply to add complexity, nor have the sign of complex changings, so it is argued that they cannot explain the sudden emergence of a system as complex as grammar.

Apart from above views, anther prediction of synthesis is "niche construction"- a process that organisms construct and modify their own environment which can then change the selection of traits that are adaptive [6], can hasten evolutionary change. This might have and perhaps accelerated evolutionary change during the Pleistocene, this would imply a gestation period of some 2 million years rather than a sudden change within the past 100,000 years [3]. However, some archeological evidence for the "human revolution" has also been questioned, implying these changes should be continuous and can be traced back to precursors of Homo sapiens, or that sign of changes should be a question of sporadic regional variation than of discontinuity through time.

As we can see, the whole process of studying biological evolution is a constantly of hypothesis, then overturned and re-hypothesis, and it is also confirmed that exactly owing to the innovation of research methods and the discovery of multi-factor evidence so that further promote the research of evolution in biology.

\section{Language Properties}

\subsection{Unity and Diversity of Language}

When humans realize it, language has appeared in the world in various forms. Why there is more than one language in the world, or in other words, in fact why language exists so many states and diversity. As early as 50 years ago, the theoretical linguist Martin Joos proposed that "there is no preexisting schema of what a language must look like". Studies of structuralism are similar, focusing almost exclusively on phonology and morphology. In terms of representation, languages in these fields are indeed different, not only in a wide range, but also in complex forms.

In fact, the question of how to harmonize unity and diversity often occurs in both linguistics and biology. Trying to describe all the linguistic phenomena and changes in more than 5000 languages in the world is a huge project.

Darwin's The Origin of Species has a famous saying, "from such a simple beginning, the most beautiful and wonderful types of endlessness have been and are going on". This is consistent with Cuvier's emphasis on biological diversity. 
Just as language produces thousands of variants in the process of externalization. These words are used as introduction titles by Sean B. Carroll, but actually their ideas were surprisingly consistent. However, Turing believes that "true biology should regard every living organism as a special law applicable to physics and chemistry, which strictly restricts their possible diversity and determines their basic characteristics." Chomsky agrees with him.

Research methods of modern natural science tend to draw on the earlier general methods of D'Arcy W. Thompson and Alan Turing's in limiting the principle of organic diversity. True biology should treat every living organism as a special rule system that can be applied to physics and chemistry, which strictly limits their possible diversity and determines their basic characteristics [10].

While, no matter how complex the animals are, or how they appear in an explosive the way, they are different but have similar genomes. That's because they use similar or specific combinations of genes during evolution. The question of uniformity had already been noticed. Darwin's companion Thomas Huxley's naturalism study made him somewhat confused and commented: there seems to be a "previously determined thing" that caused natural selection to "produce an infinite quantity and types" for each species. So, we can also boldly assume that the development of language to today's various situation, there will always be a certain degree of similarity, which is similar to the "family resemblance" in cognitive perspective. That is to say, each member has direct or indirect similarities with other members, because they are essentially unified and generated by the language faculty in the brain. The famous theory of Chomsky, principles and parameters, is to explain this problem. Language is made up of constant and immutable variables that are associated with a parameter switch box. Based on current data, children learn the rules of their own native language variants from limited language variations. For example, children need to decide whether they choose the phrase pattern like English of "head word ahead", such as eat an apple, or to choose the phrase pattern like Japanese of "head word behind", such as ringo o taberu (Apple eat). Principles and parameters also provide a theoretical framework for understanding how intrinsic unity leads to the emergence of infinite diversity.

On account of that, the diversity of languages is triggered in this way: principles do not provide answers for all languages but leave some questions to open parameters [10]. In the process of externalization of the internal computing system to sensorimotor system, language shows diversity. Externalization is not a simple task. The entire implementation process is complex and diverse, which is also affected by historical events. Most or even all parameterization and diversity will be limited to externalization parts.

\subsection{Thinking and Recursiveness}

The greatest characteristic of human language is the unity of thinking and recursiveness. 
For a long time, it has been recognized that the systematic function of language is communication. But what makes us question is that animals also communicate, such as bees dancing, birds singing to attract opposite sex, and their communication is also intended. However, the human language is so special that serves as a tool of thinking. Chomsky divides language into internalized language and externalized language. He pays attention to the generation and implementation of internalized languages in the brain, and this is the main part of generating infinite hierarchical language expression. Internalized language is silent, accompanied by the production of thinking. Therefore, language can be based on a recursive generation system that selects basic elements of the word from the lexicon (the repository of morpheme atoms) and then reuses them to create infinite expressions. "Slight rewiring of the brain" produces computational operations, access to the "lexicon" and generate of language of thought (LOT), the ability to produce thought, planning and organization of action in an infinite range. Chomsky points out that externalized language can't produce LOT, and linear lexicon is only reflected in internalized language. The process of internalization and externalization of language is often asymmetrical, and externalization is secondary.

It is necessary for us to understand the unique characteristics of human language. "The language ability shared by humans allows us to construct and understand discrete, infinite, hierarchical expressions... language is based on a recursive generator that comes from a certain repository (we call it the lexicon) and select the basic elements similar to words, and then use them repeatedly to create an infinite structural expression" [10]. Recursiveness is human-specific, which makes Language is of hierarchical structure rather than only of linear structure manifested by animals. The lexicon in the brain provides the basis for the generation of infinite sentences. To explain the generation of language, we have to face at least two processes, the first is the lexicon system, which is mentioned above, and the second is the computational system of language faculty. These are two different sections, and only to connect the two together so it can produce the expressions of externalized language. Connecting the intrinsic mental objects and externalized expressions requires two interfaces, one is the thought system (generate logic form) and the other is the sensorimotor system (generate phonetic form) [10]. The thought of language and computational mode formed in the brain is transmitted to sensorimotor system through conceptual interface, thus externalized into infinite sentence expression. The logic form is generated in a high-speed calculation in the thought system. Actually, this explanation of language generation has already emerged since the time of Aristotle, which is a reinterpretation of the traditional view that products of connection between the voice and meaning of language. Nevertheless, the reality is that the troubles of modern issues are often more serious.

Then, how to explain recursion of thinking patterns? To answer that, we need to turn back on the biological nature of language faculty. Chomsky's explain is 
that, it seems occurred at some point between 50,000 and 100,000 years ago, in the timeline of evolution, its emergence is just like a blink of eyes. From the perspective of biological evolution, Darwinian scholars believe that genetic variation is a continuously gradual change under the conditions of natural selection. Without exception, modified and evolution of evolution theory cannot perfectly explain the generation of human language competence. Whether Modern Synthesis, Punctuated evolution, or Niche construction none of them can perfectly and fully explain how language appeared among such a mutational way nor to explain why the time is in so short an evolutionary period.

However, even in the case of numerous human evidences questioning each other, we still have clues and hints. We need to find the answer of two questions: 1) whether the human language is recursive. The answer is absolute yes. Fitch also agrees with that despite his supporting of gradualism. Fischmeister and Fitch et al. [11] point that humans generate recursive hierarchies in a variety of domains, including linguistic, social and visuo-spatial modalities. Recursiveness actually exists, and he suggests our unique capacity to use and acquire language consists of multiple interlocking subcomponents, some of which are shared with other species [12]. 2) Recursiveness distinguishes human language competence from animals, that is to at least on the basis of biology, compared with gorilla, our genes had been mutated. But whether it is a continuous evolutionary natural selection behavior, or a sudden subtle reorganization of the brain rewiring during hypothetic period, which is no fully plausible explanation yet. For example, there are two types of sticklebacks, one with a thorn on the pelvis and the other is not. About 10,000 years ago, a thorn-related gene switch box was mutated, one adapted to the ocean and the other to the lake. The evolution process in turn affects the evolution of eyes, some are restricted by the physical properties of light, and the other part of the fish is affected by the opsin molecules. These opsins encoding genes originate very early and been reused but in limited ways, which is also result by affection of physical factors. This kind of evolution of eyes suggests that among the possibilities offered by a narrow physical channel, physical laws, stochastic processes, and selection effects interact with each other. Therefore, at least in my opinion, the emergence of language faculty is indeed a sudden event in a certain period, but the prerequisites and physical environment still cannot be ignored and underestimated.

\section{Is Language Unique to Human?}

\subsection{Language and Speech Organs}

Speech organ is an important material medium for human language production of human language. Early on, linguists have tried to test the language ability of human beings by the reconfiguration of the vocal tract. For example, Lieberman once reconstructed Neanderthal's speech organs to test the possibility of Neanderthals producing the three common vowels of human language: /a/, /i/, /u/. By comparing the laryngeal positions of newborns and Neanderthals, besides the 
corresponding features of the shape of their skulls are very similar, they found that the position is very similar, the size is comparable. After test, although the speech organ of Neanderthals can't pronounce the most different vowel among three of them, however, can phonate a series of other vowels. Therefore, Lieberman and colleagues think although Neanderthals could not pronounce the modern phonemes, but their speech organs have already shown limited signs of language voice, which they assumed that Neanderthals may have a special "language".

Perhaps the sounds of a two-week-old baby do not bear any resemblance to an adult's speech. However, infants aged $9-15$ months are able to produce most of the vowels in adult's speech. what's more, oral cavity and laryngeal structures may undergo significant changes after one year of birth, but these changes may not fundamentally eliminate the difference between infants' type of vocal tract (Neanderthals' similar with) and the vocal tract with fully grasping speech. Therefore, the study of the physiological structure of speech organs cannot make a convictive judgment for the property and degree of evolution of Neanderthals' pronunciation ability.

In fact, except for the reconfiguration of the vocal tract, a second crucial component of the human speech capacity remains poorly understood, that is, our highly-developed capacity for complex vocal imitation. Imitation is a prerequisite for language communication: without the ability to generate and acquire a large, open-ended vocabulary, the flexible, expressive power of language would be vastly reduced [13]. For example, Nonhuman primates are highly constrained in imitation, but for birds, seals, bats and cetaceans who can easily learn to imitate vocalizations [14]. While apes can easily learn to recognize 100s of words [15], they cannot readily learn to produce any of them. Apparently, these main limitations of non-human primates are at a neural controlled by brain and not a peripheral anatomical level. Vocal imitation and evidently requires neural abilities which is not available in nonhuman primates, such as detailed voluntary control over vocalization and an ability to link auditory input to corresponding motor outputs [16]. It still worthy to debate whether vocal imitation is at a specific domain or it justa special case of a more general imitative ability [17] [18].

However, this kind of complex, flexible semantic communication needs a more comparably complex, flexible phonological system to generate the signals. Obviously, this set of vocal system is not available to our closest relatives such as chimpanzees, or any other known nonhuman primate.

In addition to the production mechanisms, certain components of the speech perception system posed by human are potentially unique. Liberman et al. believe that speech relies on perceptual mechanisms that are unique, both to our species and to speech itself. But this kind of hypothesis is also not fully acceptable, because some evidence show that many putatively "special" aspects of speech perception now appear to be widely shared, such as categorical perception [19] and the closely-related "prototype magnet" effect [20], vocal tract nor- 
malization [21], and discrimination among human languages by rhythmic cues [22]. But we can't deny that some special perceptual mechanisms are truly uniquely posed by our species, such as music or other nonspeech sounds. Martins and his colleagues have shown that recursion is available in the visuo-spatial domain [23] and that its use does not require language resources. Later, they [24] further study musical signals of recursion reflected in musicians and non-musicians in the auditory domain, which manifests recursion can be processed in the non-linguistic auditory domain, but that the capacity to form recursive representations strongly correlates with the same ability in the visual and action sequencing domains. In the evolutionary period, only human is a perfect specie to successively compete the whole process. So, despite of the common shared vocal signs, we still have some thinkable vocal and non-vocal signs, which is a part of human language competence. So, at least, Liberman's hypothesis is still can nicely summarized by the claim that "speech is special".

\subsection{Language and Thought}

A few years ago, in a study of Denisovan Cave at the Altai Mountains of southern Siberia, researchers sequenced a girl's genome, who is named Denny, and found that about $40 \%$ of her DNA fragments matched Neanderthals' and about 40\% matched Denisovans'. Later archaeological excavations have shown that there may be three kinds of people living in the same place at Denisova Cave, namely, Denisovans, Neanderthals and homo sapiens. So these three kinds of people are likely to have verbal communication during the hybridization. In addition, archaeological evidences show that Neanderthals have signs of funeral culture and cave paintings, and they also dress themselves with jewelry and pigments made of feathers and shells. what's more, symmetrical bear's bones are also found in the caves. This sense of neat symmetry and various cultural signs may imply that Neanderthals have symbolic thinking, thus suggesting the possibility of existence of language.

However, Панов, Е.H. questioned and cited another example, "Cranes living on the rocky cliffs in the Soviet Union build mud nests on steep stone walls. Once they finish to build their nests, they will find strong feathers and insert them into the crevices next to the nest. Even if that seems asymmetric, one of the young birds can already see symmetry when playing with his building blocks and stained glass." The Soviet philosopher Семёнов pointed, "the activity of making tools must first appear in the form of reflection peculiar to animals. Its property is not conscious, purposeful, but reflective..." [25]. Although archaeological findings show that Neanderthals have cultural signs and some advantages in use of visual sense and tools, but there is no conclusive evidence proving Neanderthals have language.

Michael [3] advocates to regard language as communication, not thought, to reduce the burden of explaining language evolution. He suggests that thought can be considered to have precursors in nonhuman animals, and can be attri- 
buted to an enhanced capacity to share knowledge and experience, so thoughts themselves, whether derived from personal experience or from communication with others, are not the same as the language in which they are expressed. At least, the nature and structure of thought have a long and gradual evolutionary history. Of his view, the emergence and function of language and thought are totally different, language for communication and thought gained mostly from experience collection, which is probably to explain their different timeline of emergence. However, he ignores the most important thing is that without some specific experience collection, children still can produce some new sentences that they never seen or heard with a logical thinking pattern. Say the least of it, thought is not independent of language, and language itself can state what you think in your mind.

Chomsky once used a classic example to explain the uniqueness of human logic of thinking. "Birds that fly instinctively swim" is ambiguous. The adverb "instinctively" can either modify the preceding verb "instinctively fly" or modify the following verb "instinctively swim". But actually, the desire to "instinctively fly" appeal to children. Chomsky explains that we don't comply with the left-to-right sequential linear order when we understand the ambiguous sentence, because human syntactic structure is grounded on hierarchical structure. Suppose that we extract the adverb from the sentences, forming "instinctively, birds that fly swim", then the ambiguity is eliminated, because the adverb is construed only with the remote verb swim. If we draw a tree diagram with hierarchical structure, we will clearly find that though instinctively is closer to fly in terms of linear order, in the tree "instinctively" is closer to swim in the structural distance, which swim is embedded one level down from instinctively, but fly is embedded of two levels. Children unconsciously know that judging ambiguity of the sentence need to base on structure and don't make mistakes, which proves that the structured hierarchy of language and thought is innate acquired rather than learnt. So, we can see that neither language nor thought is not simply following the left-to-right sequential linear order. And structure dependency is only shown in human brain at a very early time.

\subsection{Language and Genes}

FOXP2 is the first gene found to be associated with language. In the 1990s, British scientists discovered, many members of the KE family have speech disorders, called developmental verbal dyspraxia. Researchers further observed three generations of the family, and the results show that all three generations have different degrees of speech disorders [26]. This has led scientists to suspect that their language disorder is genetically determined. Later on, researchers have found a British boy called CS who does not belong to the KE family, also suffers from congenital speech disorders. Lai et al. [27] found that the same gene mutated both in CS and KE family. The language-related gene (SPCH1) isolated by Lai et al. was named FOXP2. Fisher [28] pointed FOXP2 can act as both a re- 
pressor and an activator under certain conditions. FOXP2 supports development and function of a subset of neuronal circuits, including those relevant to motor skills and vocal behaviors; and that such circuits may be especially sensitive to gene dosage. Therefore, FOXP2 protein can turn on or off many other genes or regulate the expression of other genes. Three change of amino acid in the evolution of FOXP2 may cause a "slight rewiring of the brain"-affecting the cortical-basal ganglia circuit of the brain, resulting reorganization of existing evolutionary systems in a novel way, triggering the evolution of language, which play an important role in origin of human language.

Early Neanderthals can be divided into Typical Neanderthals and Progressive Neanderthals. What is interest is that by genome sequencing the two types had hybridization. Moreover, Neanderthals are constantly migrating. Evidence of interbreeding between Neanderthals and Denisovans has also been found in Denisovan caves in the Altai mountains. Evolutionary studies of language genes show that FOXP2 is found in Neanderthals and Denisovans, as well as gorillas, rhesus monkeys, songbirds and mice. Scientists have sequenced the genomes of Neanderthals and Denisovans, and it turns out that about 2\% of the DNA of early Homo outside Africa are related to Neanderthals, including FOXP2. Enard and colleagues [29] believe that the conservation of FOXP2 and the positive selection of amino acid changes are very important for the evolution of language. Therefore, it may be in the process of conservative evolution and positive selection of this gene, which make the difference of FOXP2 among human, animals and Neanderthals and further influence the appearance of language competence.

However, recently, Atkinson et al. [30] gave a new study, which re-evaluates genomic variation at the human FOXP2 locus. The new study reveals that there is no evidence for recent selection at FOXP2 among diverse human populations, which means that the two amino-acid substitutions were more likely already fixed in the common ancestor of Neandertals and modern humans, who lived at least 400 thousand years ago [31]. Atkinson et al. perform a thorough investigation of modern human FOXP2 variation, making use of genome sequences available from diverse populations across the world. Researchers found that the protein-coding sequence of FOXP2 in Neandertals matched that of Homo sapiens. The new results overturn Enard et al.'s [29] previous assertion that FOXP2 mutations are human-specific. The article also points, "We do not find evidence of recent positive or balancing selection at FOXP2". Atkinson refutes Enard's view that the original two amino acid substitutions were targeted by a recent sweep limited to modern humans $<200$ kya. One of the authors, Dr. Brenna Henn Notes, "there are serious European-centric biases in many medical and other scientific studies, and the original screen for selection investigated only part of FOXP2 in 20 humans from different continents and most of the recipients were of Eurasian descent". So the new study, they try to reanalyze FOXP2 with larger and more diverse data sets, especially in more African populations, and use more advanced modern sequencing techniques for genome-wide data. 
Nevertheless, the lack of recent selection at FOXP2 does not deny its relevance for key aspects of our biology. In fact, Elizabeth et al. don't question the role of FOXP2 in language production, but the puzzles of FOXP2 are more complex than they think.

FOXP2 is not a determinant of language competence. After FOXP2, scientists have confirmed that other members of fork head proteins, FOXP1 and FOXP4 are also members of the language genome. In the evolution of the gene, its underlying genomic architecture is undeniably complex, involving interacting networks of myriad different genetic factors, which may cause great differences in language abilities among homo sapiens, animals and Neanderthals. Therefore, although homo sapiens and Neanderthals both have FOXP2, due to the complexity of gene and evolution, more evidence is needed to solve the language puzzle. With the advancement of science and technology and more hypotheses proposed, there may be more evidence shown up in the future to unlock this mystery.

\section{Conclusions}

First of all, to answer the question of last section-Is language unique to human? The answer is yes. Although, from the perspective of relation between language and speech organ, thoughts and gene, other primates and songbirds also show up existence of signs, or more or less similar to humans. But from the results of evolution, these animals do not have language, especially for language competence, in other words, at least we can say in the chain of language evolution, they don't rush to the end. There are always some missing pieces in the process, which is only possessed by human-recursiveness, fully evolved. Language is not merely used for communication, and verbal language is also not the only constituent in daily life. Non-verbal languages, thinking languages, computing languages and logical languages are all the formation of language. The biggest difference between humans and animals is the evolution of internalized language. Many animals did not break the shackles of biological evolution, and ultimately ended in failure. Stimulus signals and linear order thinking pattern of animals are actually a compromise to the evolution of reality. That is to say, in the process of language evolution, human beings may not be perfect, but at least are successful and therefore language is unique.

Biolinguistics is interdisciplinary with a long history of development in western but quite young in China [32]. So domestic research is still in initial stage. Over the past 60 years, biological mechanisms and evolution of language have been the core of research and discussion. Origin of language at the old ages fully covered with myth. Study of the origin of language has experienced from a mythological stage to an academic discussion with a philosophical foundation, which was experienced for hundreds of years. This is a huge advancement and undoubtedly the first peak of the study of language origin. Although the discussion of the topic was once banned due to religious and social factors, finally, in 
the 1970s, Chomsky's view led to a major revolution in the discussion of language generation, and made people turn their eyes on the intrinsic nature of language it self. Chomsky proposed that there are three core questions needed to answer for biolinguistics: 1) what language is; 2) how language is acquired; 3) how language is used. The three questions are essentially basic philosophical questions, which is to further find the nature of world and human language, pursue human properties, and question closely the subjective initiative of human beings in world practice. It can be seen that the development of biolinguistics has a profound philosophical foundation. The most important thing is that it redefines the nature of language and abstract language as "an organ of the body" [33]. This provides theoretical support for language evolution. Since the 1970s, generative linguists have believed that human language are with biological properties. This scientific belief is endorsed and accepted by many geneticists and modular biologists. Therefore, the origin of biolinguistics can be attributed to the generative linguistics represented by Chomsky.

In recent years, change of theory of evolution has also been constantly revised, overturned, and confirmed. With the development of modern experimental technology, more and more experimental methods have been applied in genome sequencing and comparative research. In fact, the rise of biolinguistics has also directly benefited from new discoveries in biology and neuropsychology and other fields. It is mainly manifested in 1) the continuous challenge to the theory of evolution, such as the proposition of Modern Synthesis, the later Extended Evolutionary Synthesis, Punctuated Evolution, Evo-devo, Niche Construction and so on. Among them, Evo-devo coincides with the anti-behaviorism support by Chomsky, so Evo-devo is introduced into biolinguistics. However, some of newborn evolutionary theories are not always in favor of Chomsky's viewpoint, and his view is not unshakeable. It is undeniable that those dissenting ideas are generated on the basis of him, bring about more theoretical proposals which promote to find more evidence for studying language evolution; 2) understanding of the central issues in language-related interdisciplinary. In fact, challenges of interdisciplinary are also unquestionable, that is, cross-disciplines lack a common representational surface compared with a single discipline. It is especially important to look for universality from individuality; 3) an exhaustive description of the biological attributes of language. Language is no longer linked to genes merely. Speech organs, thoughts, and computing systems in the brain are all expressions of biological attributes to language. Therefore, this provides us with a broader horizon on research; 4) the latest research finding of FOXP2. FOXP2 has been given the title of "language gene" since born [34]. Recent studies have shown that FOXP2 is not the only one gene effect to language. What's more, there is no evidence for recent selection at FOXP2 among diverse human populations, which means that the two amino-acid substitutions were more likely already fixed in the common ancestor of Neandertals and modern humans; 5) The formation and development of the Minimalist Program in linguis- 
tics. It is the emergence of the Minimalist Program that makes linguistics closely related to cognitive science and other subdisciplines of bioscience.

In the area of biolinguistics, opportunities and challenges both exist for researchers. Opportunity is the development and improvement of the Minimalist Program. However, the biggest challenge for researchers is whether they have an open mind and whether they can think diversifiedly and multifactorially. Different theoretical assumptions are not completely mutually exclusive; on the contrary, linguistic study based on different theories benefits to explore the complexity of human language organs. We do not deny those views. With the development of human knowledge and the continuous integration of Humanities and natural sciences, there will be more enlightenment for the exploration of the origin and development of language. Although Chomsky's views on biolinguistics are still controversial, there is no doubt that in the early development of biolinguistics, Chomsky's standpoint of bio-heritability of language points out the direction for the development of biolinguistics. Therefore, in the way of future research, we should combine more biological and interdisciplinary multi-factors with advanced scientific means, so as to accumulate more empirical evidence and make hypotheses to reveal those secrets behind language evolution.

\section{Acknowledgements}

I am very grateful to my supervisor Prof. Daoshan Ma for his patient guidance, valuable suggestions and constant encouragement and comments, which have prompted many useful revisions to this paper. His enlightening idea, fund of knowledge and unfailing support help me a lot. Thanks also to Open Access Library Journal for giving me the opportunity to clarify many of my thoughts to the world.

\section{Conflicts of Interest}

The author declares no conflicts of interest regarding the publication of this paper.

\section{References}

[1] Ferretti, F., Adornetti, I., Chiera, A., Cosentino, E. and Nicchiarelli, S. (2018) Introduction: Origin and Evolution of Language-An Interdisciplinary Perspective. Topoi, 37,219-234. https://doi.org/10.1007/s11245-018-9560-6

[2] Schreyer, R. (1985) The Origin of Language: A Scientific Approach to the Study of Man. Topoi, 4, 181-186. https://doi.org/10.1007/BF00135846

[3] Corballis, M.C. (2017) Language Evolution: A Changing Perspective. Trends in Cognitive Sciences, 21, 229-236. https://doi.org/10.1016/j.tics.2017.01.013

[4] Chomsky, N. (2015) Some Core Contested Concepts. Journal of Psycholinguistic Research, 44, 91-104. https://doi.org/10.1007/s10936-014-9331-5

[5] Darwin, C. (1968) On the Origin of Species by Means of Natural Selection. Murray, London, 502.

[6] Laland, K.N., Uller, T., Feldman, M.W., et al. (2015) The Extended Evolutionary 
Synthesis: Its Structure, Assumptions and Predictions. Proceedings of the Royal Society B: Biological Sciences, 282, Article ID: 20151019.

https://doi.org/10.1098/rspb.2015.1019

[7] Pinker, S. and Bloom, P. (1990) Natural Language and Natural Selection. Behavioral and Brain Sciences, 13, 707-727. https://doi.org/10.1017/S0140525X00081061

[8] Gould, S.J. and Lewontin, R.C. (1979) The Spandrels of San Marco and the Panglossian Paradigm: A Critique of the Adaptationist Programme. Proceedings of the Royal Society of London. Series B. Biological Sciences, 205, 581-598. https://doi.org/10.1098/rspb.1979.0086

[9] Gould, S.J. and Eldredge, N. (1977) Punctuated Equilibria: The Tempo and Mode of Evolution Reconsidered. Paleobiology, 3, 115-151.

https://doi.org/10.1017/S0094837300005224

[10] Chomsky, N. (2010) How to Look Today's Biolinguistics Program. Linguistic Sciences, 2, 113-123.

[11] Fischmeister, F.P., Mauricio, M.J.F., Beisteiner, R. and Fitch, W.T. (2016) Self-Similarity and Recursion as Default Modes in Human Cognition. Cortex, 97, 183-201. https://doi.org/10.1016/j.cortex.2016.08.016

[12] Fitch, W.T. (2018) Bio-Linguistics: Monkeys Break through the Syntax Barrier. Current Biology, 28, 695-717. https://doi.org/10.1016/j.cub.2018.04.087

[13] Fitch, W.T. (2005) The Evolution of Language: A Comparative Review. Biology and Philosophy, 20, 193-203. https://doi.org/10.1007/s10539-005-5597-1

[14] Janik, V.M. and Slater, P.J.B. (1997) Vocal Learning in Mammals. Advances in the Study of Behaviour, 26, 59-100. https://doi.org/10.1016/S0065-3454(08)60377-0

[15] Savage-Rumbaugh, E.S., Murphy, J., Sevcik, R.A., Brakke, K.E., Williams, S.L., Rumbaugh, D.M. and Bates, E. (1993) Language Comprehension in Ape and Child. Monographs of the Society for Research in Child Development, 122, 231-263. https://doi.org/10.2307/1166068

[16] Jürgens, U. (1998) Neuronal Control of Mammalian Vocalization, with Special Reference to the Squirrel Monkey. Naturwissenschaften, 85,376-388. https://doi.org/10.1007/s001140050519

[17] Donald, M. (1991) Origins of the Modern Mind: Three Stages in the Evolution of Culture and Cognition. Harvard University Press, Cambridge.

[18] Moore, B.R. (1992) Avian Movement Imitation and a New Form of Mimicry: Tracing the Evolution of a Complex Form of Learning. Behaviour, 122, 231-263. https://doi.org/10.1163/156853992X00525

[19] Kuhl, P.K. and Miller, J.D. (1978) Speech Perception by the Chinchilla: Identification Functions for Synthetic VOT Stimuli. The Journal of the Acoustical Society of America, 63, 905-917. https://doi.org/10.1121/1.381770

[20] Kluender, K.R., Lotto, A.J., Holt, L.L., et al. (1998) Role of Experience for Language-Specific Functional Mappings of Vowel Sounds. The Journal of the Acoustical Society of America, 104, 3568-3582. https://doi.org/10.1121/1.423939

[21] Fitch, W.T. (1997) Vocal Tract Length and Formant Frequency Dispersion Correlate with Body Size in Rhesus Macaques. The Journal of the Acoustical Society of America, 102, 1213-1222. https://doi.org/10.1121/1.421048

[22] Ramus, F., Hauser, M.D., Miller, C., Morris, D. and Mehler, J. (2000) Language Discrimination by Human Newborns and by Cotton-Top Tamarin Monkeys. Science, 288, 349-351. https://doi.org/10.1126/science.288.5464.349

[23] Martins, M.J.D., Muršič, Z., Oh, J. and Fitch, W.T. (2015) Representing Visual Re- 
cursion Does Not Require Verbal or Motor Resources. Cognitive Psychology, 77, 20-41. https://doi.org/10.1016/j.cogpsych.2015.01.004

[24] Martins, M.D., Gingras, B., Puig-Waldmueller, E. and Fitch, W.T. (2017) Cognitive Representation of "Musical Fractals": Processing Hierarchy and Recursion in the Auditory Domain. Cognition, 161, 31-45. https://doi.org/10.1016/j.cognition.2017.01.001

[25] Панов, E.H. (1983) Can Neanderthals Speak? Contemporary Linguistics, 1, 50-57.

[26] Dong, Y.Z. and Zhang, R. (2009) New Horizons in the Study on the Biological Mechanism of Language: FOXP2 and Human Language Faculty. Journal of Northeastern University (Social Science), 4, 355-359.

[27] Lai, C.S.L., Fisher, S.E., Hurst, J.A., Vargha-Khadem, F. and Monaco, A.P. (2001) A Forkhead-Domain Gene Is Mutated in a Severe Speech and Language Disorder. Nature, 413, 519-523. https://doi.org/10.1038/35097076

[28] Fisher, S.E. (2005) Dissection of Molecular Mechanisms Underlying Speech and Language Disorders. Applied Psycholinguistics, 26, 111-128. https://doi.org/10.1017/S0142716405050095

[29] Enard, W., Przeworski, M., Fisher, S.E., Lai, S.L., Wiebe, V., Kitano, T., Monaco, A.P. and Pääbo, S. (2002) Molecular Evolution of FOXP2, a Gene Involved in Speech and Language. Nature, 418, 869-972. https://doi.org/10.1038/nature01025

[30] Atkinson, E.G., Audesse, A.J., Palacios, J.A., Bobo, D.M., Webb, A.E., Ramachandran, S. and Henn, B.M. (2018) No Evidence for Recent Selection at FOXP2 among Diverse Human Populations. Cell, 174, 1-12. https://doi.org/10.1016/j.cell.2018.06.048

[31] Fisher, S.E. (2018) Human Genetics: The Evolving Story of FOXP2. Current Biology, 29, 65-67. https://doi.org/10.1016/j.cub.2018.11.047

[32] Zhao, Y.G. (2018) Explanations on the Evolution of Language and the Forward Road of Bio-Linguistics: Concurrent Comments on Why Only Us: Language and Evolution. Academic Exploration, 6, 107-116.

[33] Berwick, R.C. and Chomsky, N. (2016) Why Only Us: Language and Evolution. MIT Press, Cambridge. https://doi.org/10.7551/mitpress/9780262034241.001.0001

[34] Wu, H.Q. (2012) Language, Brain and Memory: Some Interdisciplinary Approaches to Linguistics. Zhejiang University Press, Hangzhou. 